\title{
Evaluation of Environmental Impact and Risk Assessment Methods of Industrial Buildings in Malaysia
}

\author{
Ezyana Anyzah Marmaya, Rohana Mahbub \\ Faculty of Architecture Planning and Surveying, \\ Universiti Teknologi MARA, Shah Alam, Selangor, Malaysia \\ e_anyzah@yahoo.com
}

\begin{abstract}
To ensure high performance of projects, risk factors and their impact towards the environment need to be addressed during and after the construction phase. This research aims to assess the risk factors and the impact of industrial projects to the environment and surrounding areas. The research employs multi-method strategies: this case study of SAMUR, Sabah includes several interviews, observations, analysis of project documents and questionnaires distributed among the occupants living in the surrounding area. The results of the research indicated that the project is perceived to have negative environmental impact measured under ecosystem, natural resources, and public impact.

Keywords: risk assessment, risk factors, environmental impact, industrial projects, Malaysia

eISSN 2398-4279 @ 2018. The Authors. Published for AMER ABRA cE-Bs by e-International Publishing House, Ltd., UK. This is an open access article under the CC BY-NC-ND license (http://creativecommons.org/licenses/bync-nd/4.0/). Peer-review under responsibility of AMER (Association of Malaysian Environment-Behaviour Researchers), ABRA (Association of Behavioural Researchers on Asians) and CE-Bs (Centre for EnvironmentBehaviour Studies), Faculty of Architecture, Planning \& Surveying, Universiti Teknologi MARA, Malaysia.

DOI: https://doi.org/10.21834/ajqol.v3i13.160
\end{abstract}




\subsection{Introduction}

The high depletion rate of natural resources and the increasing consumption of nonrenewable resources particularly in the construction industry has led to environment deterioration (Ali, Jainudin, Tawie, \& Jugah, 2016). Rapid urbanization and the pursuit of a better quality of life has caused Malaysia to shift towards environmental degradation resulting from the series of challenges evolving from environmental issues (Mei, Wai, \& Ahama, 2016). These issues could stem from various causes including unsustainable construction practices. The concept of sustainable development parallels the principles of Quality of Life through community involvement (Kamaruddin, Ahmad, \& Alwee, 2016). According to Annod (2014), many construction projects suffer from mismanagement despite continuous improvement in the field of project risk management. From the general overview, the lack of implementation of standard risk management methods in the construction industry has led to construction projects that suffer from poor performance, and consequently give negative impact to the environment. To avoid this and other problems, a standard construction risk management model that contains an in-depth study of the construction environment needs to be designed for future use; showing that employers must have vast knowledge and awareness on the effects of their activity towards the environment. Furthermore, they must ensure that pollution is kept within the perimeters to prevent further disruptions to the surrounding community.

\section{Sabah Ammonia Urea (SAMUR)}

SAMUR project will be the case study for this paper. Based on the project documentation, Sipitang Oil and Gas Industrial Park (SOGIP), has served as a new focal point for oil and gas investment within the Sabah, Brunei and Labuan economic centres. This project (SAMUR) approximately cost RM 4.6 billion (USD 1.5 billion) and produce about 1.2 million tons per annum of granulated urea.

\subsection{Literature Review}

\subsection{Risk Management}

Risk management is a method of minimizing risk factors and maximizing opportunity factors by identifying and eliminating or mitigating, the risk factors (Park, Park, Cha, \& Hyun, 2016). Risk management is the key function of project-based organizations, and this system is designed to measure and manage all complex risks of their projects (Khameneh, Taheri, \& Ershadi, 2016). The risk management cycle (the risk assessment phase) can be viewed in three stages: risk identification, risk analysis and risk response (Zayed at al., 2008).

\subsection{Environmental Impact}

Protection of the living environment is one of the most important fields of our time, and it is more than logical that the society should pay special attention to this area (Aliu, Aliu, Mustafi, \& Kamberi, 2011). Global warming may contribute to the break-up of ice shelves and create a loss of habitat for animals dependent on the ice shelves (Hanifah \& Hashim, 2016). Climate change is a substantial energy security concern not only because direct flooding and natural 
disasters can damage power plants and transmissions lines but also because it has severe impact on food security, health, and environmental refugees that can all lower the income base of Asian countries and add to government debt, further complicating attempts at sound energy policy making (Sovacool, 2014).

\subsubsection{Impact of Construction Activity towards the Environment}

The environment is threatened severely by many problems, including those caused by the activities of construction projects (ljigah et al., 2013). For impact assessment, it should be built into the early phases and flow through along the whole planning procedures especially where resource management and land use decisions are concerned (Shafie, Omar, \& Karuppannan, 2013). The development project should be planned in such a manner that it has maximum positive impact and minimum negative impact on the environment (Kaur and Arora, 2012). Environmental impacts are categorized into three safeguard subjects, that is, public impacts, natural resources impacts and ecosystem impacts. (Li et al., 2010; Chang et al., 2011 and Zolfagharian et al., 2012).

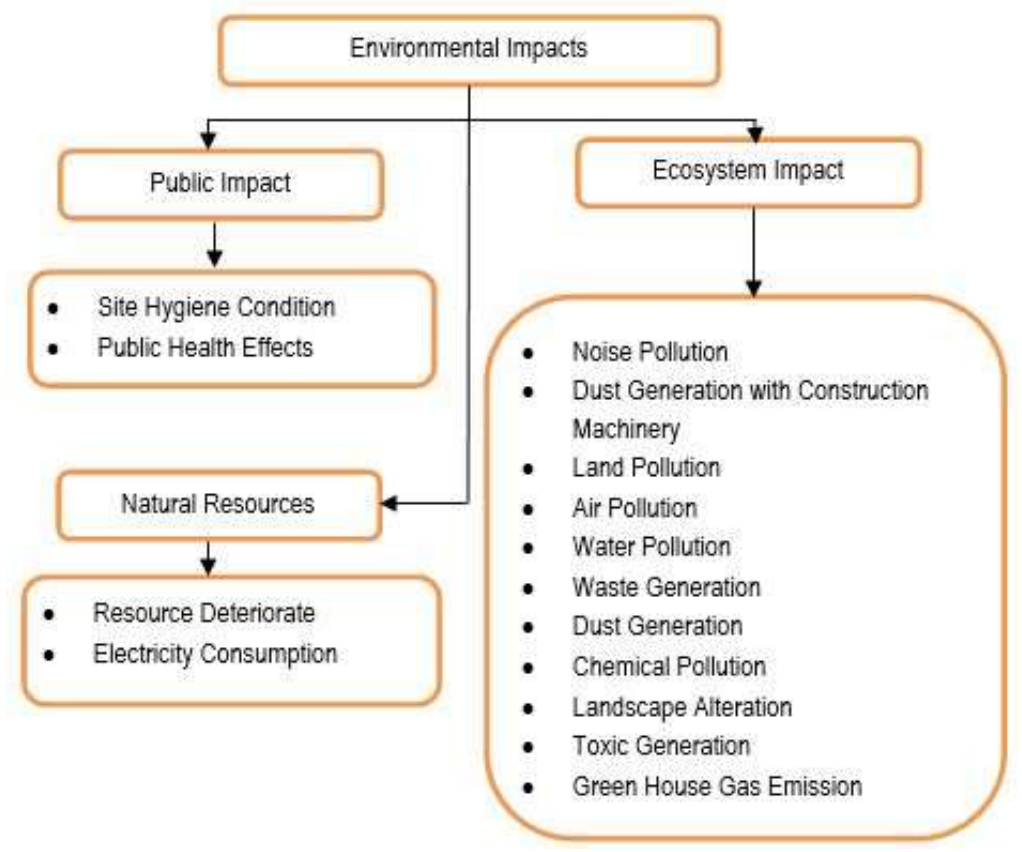

Figure 1: Environmental Impacts of Construction Processes

(Li et al., 2010; Chang et al., 2011 and Zolfagharian et al., 2012) 


\section{a) Public Impacts}

Most construction projects are located in densely populated areas. Thus, people who live at or close to construction sites are prone to harmful effects on their health because of dust, vibration and noise due to certain construction activities such as excavation (Li et al., 2010).

\section{b) Natural resources impacts}

Construction equipment operations consume a lot of natural resources, such as electricity and diesel fuel. The construction sector is responsible for consuming a high volume of natural resources and generating a great amount of pollution as a result of energy consumption during extraction and transportation of raw materials (Li et al., 2010; and Zolfagharian et al., 2012).

\section{c) Ecosystem impacts}

The accumulated amount of adverse environmental impacts such as waste, noise, dust and hazardous emissions still occur during the construction process which causes serious damages to humans and ecosystems (Chen et al., 2004; and Zolfagharian et al., 2012). With the rise in the number of construction of new buildings, the ecosystems impact of construction has become an important issue (Zolfagharian, 2012). These adverse environmental impacts include waste, noise, dust, solid wastes, toxic generation, air pollution, water pollution, bad odor, climate change, land use, operation with vegetation and hazardous emissions (Kaur and Arors, 2012).

\subsection{Methodology}

Semi-structured interviews were conducted with parties involved in the SAMUR Project, consisting of the Project Manager, Engineer and Safety Officer. It was carried out to investigate the risk assessment for SAMUR project to mitigate the environmental impact. At the same time, documentation from the SAMUR project was also analyzed to gather more information about the risk assessment procedure. For the questionnaire survey, 200 questionnaires were distributed among the community around the SAMUR project to gain their perspective on the environmental impact of the project.

\subsection{Results and Discussion}

\subsection{Risk Assessment for SAMUR}

For this project, PETRONAS Global Technical Solutions Sdn. Bhd (PGTSSB) Process Safety Management (PSM) team was engaged by Mitsubishi Heavy Industries Ltd. (MHI) to conduct a Quantitative Risk Assessment (QRA) for SAMUR project. The main purpose of the assessment was to verify if the offsite risk results meet the Department of Environment Guideline Criteria (DOE, 2004).

\subsection{Quantitative Risk Assessment (QRA)}

The basis for the current QRA study is DNV's (Det Norske Veritas) proprietary risk modeling software, PHASTRISK 6.54. The PHAST consequence modeling results are regularly 
reviewed and where required re-calibrated, based on the most recent available accident and test data. Various aspects of hazard identification were performed, to allow a definition of the failure cases, which should be consistent with the scope and objectives of the risk assessment applicable to the SAMUR project.

\subsubsection{Leak Sizes Model}

A question to address is what leak sizes to model (and specify in the failure case definition), as leak sizes may vary from pinhole leaks to equipment rupture. The following leak sizes ranges may be considered for modeling in a risk study:

- Small leaks

- Medium leaks

- Large leaks

- $\quad$ Line ruptures

- Instantaneous
1 to $10 \mathrm{~mm}$; equivalent size $5 \mathrm{~mm}$

10 to $50 \mathrm{~mm}$; equivalent size $25 \mathrm{~mm}$

50 to $150 \mathrm{~mm}$; equivalent size $100 \mathrm{~mm}$

Pipe diameter

Vessel inventory released

\subsubsection{Release Durations Model}

The following assumptions were made based on the time required to detect a leak and isolate facilities within individual process area, tank farms, and other operational areas.

- Process Areas: The time to detect a leak, investigate and then initiate an emergency shutdown is estimated as 10 minutes.

- Tanks Farms: The time to detect a leak, investigate and then initiate an emergency shutdown is estimated as 10 minutes.

- Non-isolatable Inventories: Leaks will continue until inventory is exhausted, but subject to a modeling cut-off limit of 60 minutes.

- Leaks on jetty loading arms will be isolated within 1 minute via local ESD button (attended operation).

\subsubsection{Release Surface Model}

The following assumptions were made on the release surface, which affects the extent of spill spreading and hence pool fire, pool evaporation and flash fire results. Within PHAST, the type of surface may be specified as:

- Deepwater, modeled within PHAST with a maximum spill depth of $5 \mathrm{~mm}$.

- Concrete (flat), modeled within PHAST with a maximum spill depth of $10 \mathrm{~mm}$.

- Wet soil, modeled within PHAST with a maximum spill depth of $3 \mathrm{~mm}$.

- Dry soil, modeled within PHAST within a maximum spill depth of $50 \mathrm{~mm}$.

\subsubsection{Failure Case Selection}

Consistent with the objective to create a Fully Comprehensive Risk Model, all process equipment within each process area and all flammable and toxic materials are included in the failure case definition and hence the PHST risk model, whether capable of producing an offsite risk or not. 


\subsection{Environmental Impact Assessment}

The main sensitive areas around the project site are the mangrove habitats, fishing ground, and villages. The majority of the fisherman reported a daily income ranging from RM 100 RM 500, with the catch normally sold to wholesalers. The EIA study focuses on the environmental impacts from other aspects of the plant that have been addressed in the Preliminary Environmental Impact Assessment for the Sabah Ammonia Urea (SAMUR) Plant.

\subsection{Environmental Impact for Case Study}

This study uses a questionnaire survey to measure the environmental impact to the surrounding area, and distributed among the community around the SAMUR project (Kg. Siputol and $\mathrm{Kg}$. Banting). Two hundred questionnaires were distributed and collected, giving a response rate of $100 \%$. The questionnaire was divided into five sections:

\section{a) Demographic Information}

Based on data from the two villages, the majority of the population is male, age 21-30 years old with a minimum education of SPM and equivalent. Most of the villagers in $\mathrm{Kg}$. Siputol is currently working within the government sector $(60 \%)$ and for $\mathrm{Kg}$. Banting, most are working in the private sector (52\%). The self-employed group for both villages is almost at the same percentage, as some of the villagers own businesses. The highest size of family for both villages is at "1 to 5 people"; which is $64 \%$ for both $\mathrm{Kg}$. Siputol and Kg. Banting.

\section{b) General Environmental Concerns}

For the two villages, the results indicate that the highest pollution is on resource deterioration effects and public health effects. Further investigation, through interviews, suggested that the pollution caused by the construction works proved to be unhealthy to the villagers within the community.

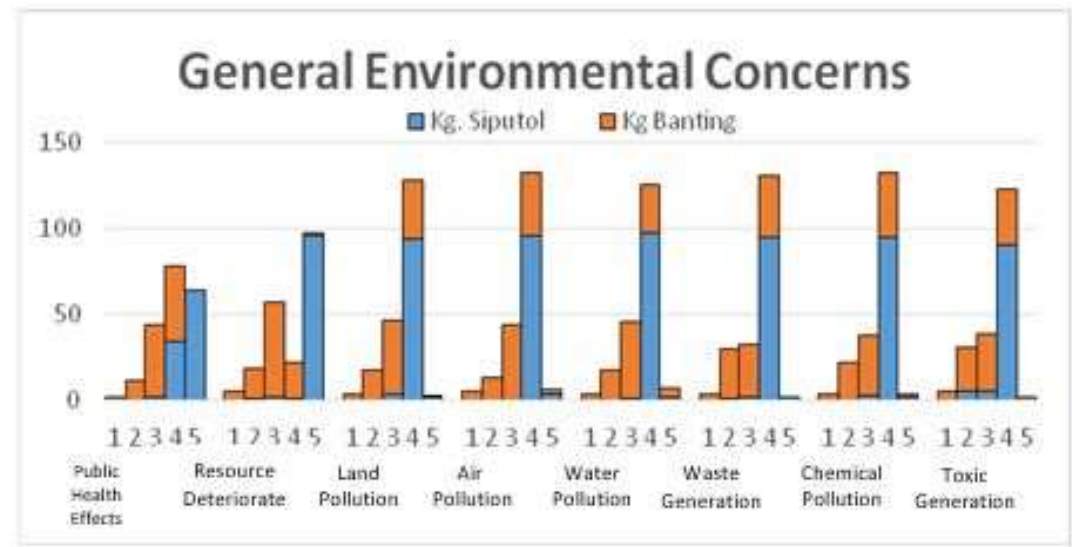

Figure 2: General Environmental Concerns

\section{c) Effect to the Community}


Section 3 measures the impact of the pollution to their properties, daily activities and the surrounding area. All the respondents (100\%) agreed that the construction had affected their activities and the surrounding area.

\section{d) Level of general environmental concerns}

In assessing the level of general concerns amongst the villagers, most strongly agree with these statements (ranked 1 to 3 ):

i) The government should provide incentives for people to look after the environment

ii) The project managers need to ascertain environment needs before starting a construction project

iii) The clients or contractors need to be responsible in monetary terms for all pollution caused by the construction activities

\section{e) General views about the environment}

Section 5 measures the general views on the environment. Most of the villagers strongly agree with the statements:

Jobs today are more important that protecting the environment for the future

I am willing to make personal sacrifices for the sake of the environment

Humans have the right to modify the natural environment to suit their needs

Nature is strong enough to cope with the impact of modern industrial nations

\subsection{Relationship between risk assessment and the environmental impact}

This study focused on the evaluation of environmental impact and risk assessment for an industrial project, due in part to the heavy pollution generated by industrial projects such as the SAMUR project. Based on the findings, it can be deduced that the community are exposed to numerous chemicals from environmental sources such as air pollution and water pollution that are generally caused by construction activities. Some of these chemicals are threats to human health and also cause damage to the environment. An overall risk assessment is important to ensure that projects are carried out in a cost efficient and safe way and for assigning priorities. For the SAMUR project, chemical waste in the river (water pollution) did not pose a great enough threat to the environment to justify a costly clean up action. Also, risk assessment is a process to evaluate the potential risks that may exist in the project, and therefore, without the risk assessment process or inspection from the QRA method, the chemical from the SAMUR project could easily leak, spill out or blow up to cause air and water pollution. As one of the important tools in risk assessment is environmental impact assessment, it enables environmental factors to be given due weight, along with economic or social factors, when applications for new projects are being considered.

\subsection{Conclusion}

This study investigated the risk assessment and the level of environmental impacts of construction for industrial buildings in Malaysia. The results demonstrate that resources deterioration has been identified as the highest environmental impact risk on construction sites. The results of the research also indicated that the industrial project is perceived to have 
negative environmental impact measured under ecosystem, natural resources, and public impact. The findings of this research can potentially be an influential assessment tool in assisting construction practitioners in improving the on-site environmental performance within the risk assessment process. Furthermore, the research is expected to enhance the existing knowledge and data on risk assessment used related to environmental issues and its impact in Malaysia. In summary, the outcome of this study can help organizations and managers prepare better sustainability plans and also increase the knowledge of partners within construction projects through training and awareness programs.

\section{Acknowledgement}

The authors would like to extend their utmost appreciation to all participants including the SAMUR project participants and the community at Sipitang Sabah for sharing their valuable time and support. The authors also acknowledge the Universiti Teknologi MARA GIP grant $600-$ IRMI/GIP 5/3 (0070/2016) for funding the research.

\section{References}

Ali,, A., Jainudin, N., Tawie, R., \& Jugah, I. (2016). Procedia - Social And Behavioral Sciences, Green Initiatives in Kota Kinabalu Construction Industry.

Aliu, A., Aliu, S., Mustafi, M., \& Kamberi, Z. (2011). Environmental pollution in the river Koselska, law, economic and social aspects. Procedia -Social And Behavioral Sciences, 462-466.

Annood Altoryman, 2014. The school of Mechanical, Aerospace and Civil Engineering: Assessment Identification in Gulf Region.

Hanifah, N. \& Hashim, R. (2016). The Madrid Protocol 1991 and its Environmental Impacts towards the Quality of Life. Procedia - Social and Behavioral Sciences, 398 - 403.

ljigah, E., Jimoh, R., O. Aruleba., B. and Ade, A. (2013). An Assessment of Environmental Impacts of Building Construction Projects. Civil and Environmental Research, Vol 3(No. 1).

Kamaruddin, S., Ahmad, P., \& Alwee, N. (2016). Community Awareness on Environmental Management through Local Agenda 21 (LA21). Procedia - Social and Behavioral Sciences, 729 - 737.

Kaur M. and Arora S. (2012), Environment impact assessment and environment management studies for an upcoming multiplex- a Case Study. IOSR Journal of Mechanical and Civil Engineering (IOSRJMCE), 1( 4): 22-30

Khameneh, A., Taheri, A., \& Ershadi, M. (2016). Offering a framework for evaluating the performance of project risk management system. Procedia - Social And Behavioral Sciences, 82-90.

Lawrence, M., Kiberu, F., Kyakula, M. and O. Batambuze, A. (2012). An Assessment of the Impact of Construction Activities on the Environment in Uganda: A Case Study of Iganga Municipality.

Li X., Zhu Y. and Zhang Z. (2010), An LCA-based environmental impact assessment model for construction processes. Building and Environment, 45(3):766-775 
Mei, N., Wai, C., \& Ahamad R. (2016). Environmental Awareness and Behavior Index for Malaysia. Procedia- Social and Behavioral Sciences. (pp. $668-675)$

Park, J., Park, B., Cha, Y., \& Hyun, C. (2016). Risk Factors Assessment considering Change Degree for MegaProjects. Procedia - Social and Behavioral Sciences, 50 - 55.

Shafie, F., Omar, D., \& Karuppannan, S. (2013). Environmental Health Impact Assessment and Urban Planning. Procedia - Social and Behavioral Sciences, 82 - 91.

Sovacool, B.K (2014). Environmental Issues, Climate Changes, and Energy Security in Developing Asia, No. 399. By Asian Development Bank ISSN.1655-5252. Publication Stock no. WPS146535Techniques, London, Financial Times-Pitman Publishing.

ZAYED, T., AMER, M. \& PAN, J. 2008. Assessing risk and uncertainty inherent in Chinese highway projects using AHP. International Journal of Project Management, 26, 408-419.

Zolfagharian S., Nourbakhsh M., Irizarry J., Ressang A. and Gheisari M. (2012), Environmental impacts assessment on construction sites. Construction Research Congress 2012: 1750-1759. 